\title{
Barreiras à criatividade pessoal: desenvolvimento de um instrumento de medida ${ }^{1}$
}

\author{
Eunice M. L. Soriano de Alencar ${ }^{2}$ \\ Universidade Católica de Brasília
}

\begin{abstract}
Resumo
Este artigo apresenta as etapas de construção e validação de um inventário de barreiras à criatividade pessoal. $\mathrm{O}$ instrumento focaliza distintas barreiras que dificultam ao indivíduo expressar seu potencial criador e incluiu, na versão original, 70 itens. Para fins de validação, o mesmo foi aplicado em uma amostra de 388 universitários, após ter sido submetido à análise semântica. Para estudo do seu conteúdo, procedeu-se à análise fatorial pelo processo de extração análise dos eixos principais com rotação oblíqua, que indicou os seguintes fatores: Inibição/timidez; Falta de Tempo/Oportunidade; Repressão Social; e Falta de Motivação. Análises preliminares indicam que o inventário discrimina distintos tipos de barreiras que afetam a expressão da criatividade pessoal, constituindo-se em instrumento útil para fins de pesquisa e diagnóstico.

Palavras-chave: criatividade; bloqueios; inventário.
\end{abstract}

\section{Obstacles to personal creativity: the development of a measurement Instrument}

\begin{abstract}
Summary
This article describes the construction and validation process of an inventory of obstacles to personal creativity. The instrument focuses different obstacles that an individual may have to express his (her) creative potential. It included, in its original version, 70 itens. The instrument was administered to 388 university students for validation purposes, after being submitted to a semantic analysis. A factor analysis (principal components, oblique rotation) was carried out to analyze the instrument content. This analysis indicated the following factors: Personal Inhibition/Shyness; Lack of Time/Opportunities; Social Repression; and Lack of Motivation. The preliminary analyses indicate that the inventory discriminates different kinds of obstacles that may interfere with the expression of the personal creativity. It is a promising instrument for research and for diagnostic purposes.
\end{abstract}

Key-words: creativity; obstacles; inventory.

Inúmeras são as barreiras que dificultam ao indivíduo tirar proveito de seu potencial para criar. Algumas delas são de ordem eminentemente pessoal e aqui poderíamos fazer referência a barreiras emocionais, perceptuais e intelectuais. Outras são de ordem social, estando diretamente ligadas a valores, normas e pressupostos cultivados na sociedade e que contribuem para manter adormecido o potencial para criar. A influência poderosa de forças adversas à criatividade presentes na sociedade ocidental é de tal ordem que Abraham Maslow, um dos psicólogos mais proeminentes do presente século, chegou a destacar que "o homem criativo não é o homem comum ao qual se acrescentou algo. Criativo é o homem comum do qual nada se tirou" (em Alencar, 1996).

A literatura sobre barreiras à criatividade é vasta. Vários autores, como Adams (1986),

\footnotetext{
${ }^{1}$ Agradeço ao CNPq pelo apoio recebido para o desenvolvimento do presente estudo, aos professores Luiz Pasquali e Maria de Fátima Bruno-Faria, pela assistência na análise de dados, Denise de Souza Fleith e Isolda Aráujo Gunther, pela leitura e sugestões ao texto, e aos bolsistas de Iniciação Científica Rebecca Ribeiro, Shyrlene Brandão e Alessando Carvalho de Oliveira, pela aplicação do instrumento.

${ }^{2}$ Endereço para correspondência: Programa de Mestrado em Educação Universidade Católica de Brasília SGAN 916 MóduloB, CEP: 70790-160-Brasília-DF - Telefone: (Oxx61) 340-5550r.155 Fax: (xx61) 347-4398 e-mail: ealencar@pos.ucb.br
} 
Alamshah (1972), Alencar (1995a, 1995b, 1996), Pames (1967), Rickards e Jones (1991) e VanDemark (1991), fazem referência aos distintos fatores que inibem a criatividade, classificandoos de diferentes maneiras. Alguns incluem as barreiras perceptuais, culturais e emocionais em suas taxonomias (como Alencar, 1995a, 1995b e Adams, 1986). Outros diferenciam entre barreiras internas e externas (Pames, 1967). E ainda outros, como Rickards e Jones (1991), apontam barreiras estratégicas, que dizem respeito às distintas abordagens de se resolver problemas, as de valores, que se referem às crenças e valores pessoais que restringem a amplitude de idéias contempladas, as de natureza perceptual, e as de auto-imagem, sendo estas últimas diretamente vinculadas a uma falta de confiança no valor das próprias idéias.

Há também alguns autores, como Arieti (1976) e Schwartz (1992), que se detiveram especialmente nos fatores sociodinâmicos da criatividade e que salientam que a criatividade não ocorre por acaso, sendo antes profundamente influenciada por fatores ambientais, considerando ainda os momentos de criação como resultantes de complexas circunstâncias sociais.

Apesar de ser vasta a literatura sobre barreiras, observa-se que os estudos empíricos a este respeito se restringem sobremaneira às barreiras existentes no ambiente de trabalho, tendo sido desenvolvidos vários instrumentos para identificar tal aspecto nas organizações. Um destes instrumentos foi desenvolvido por Amabile e Gryskiewicz (1989) e inclui tanto escalas relativas a estímulos à criatividade, como outras referentes a obstáculos à sua expressão no ambiente de trabalho. Também Isaksen e Dorval (1993) desenvolveram um instrumento denominado Questionário sobre Clima para Inovação, que inclui itens relativos ao grande número de dimensões do ambiente de trabalho, como dinamismo, abertura, tempo disponível para produzir idéias e formas de se lidar com conflitos. Tal instrumento possibilita identificar fatores incentivadores e bloqueadores à criatividade no ambiente organizacional. Outro instrumento que identifica barreiras à criatividade individual nos ambientes organizacionais foi desenvolvido por Rickards e Jones (Rickards, 1993, Rickards \& Jones, 1991). Esse instrumento, denominado Inventário Jones de Barreiras, contempla distintos tipos de obstáculos que afetam a expressão da criatividade no ambiente de trabalho. No Brasil, recentemente, Bruno-Faria (1996) e Bruno-Faria e Alencar (1996) investigaram estímulos e barreiras à criatividade no ambiente de trabalho, tendo construído um instrumento para identificar tais fatores no contexto organizacional (BrunoFaria \& Alencar, 1998). O referido instrumento, denominado Indicadores de Clima para a Criatividade (ICC), de forma similar ao desenvolvido por Amabile e Gryskiewicz, inclui um conjunto de fatores relativos a estímulos à criatividade no ambiente de trabalho, como Ambiente Físico Adequado, Incentivo a Idéias Novas, Liberdade de Ação, Salários e Benefícios Adequados, Ações da Chefia e da Organização em Apoio a Idéias Novas. Engloba também fatores referentes' a obstáculos à criatividade no ambiente de trabalho, como Excesso de Serviços e Escassez de Tempo, Resistência a Idéias Novas e Problemas Organizacionais.

Constata-se, entretanto, a inexistência, em nosso país, de instrumentos para se identificar as barreiras pessoais à criatividade. Isto levou-nos ao desenvolvimento do presente estudo, que teve como objetivo construir e validar um inventário de barreiras à expressão da criatividade pessoal, que pudesse ser utilizado tanto em programas de treinamento e desenvolvimento pessoal, quanto para fins de diagnóstico e ainda em pesquisas futuras sobre o tema. 


\section{Etapas iniciais da construção e validação do instrumento para identificação de barreiras à criatividade pessoal}

Como ponto de partida para a construção do instrumento, fez-se uma revisão de literatura sobre o tema, ocasião em que se constatou que, apesar de ser este um dos aspectos mais abordados por estudiosos da Psicologia da Criatividade, há carência de instrumentos na área.

Paralelamente a esta revisão de literatura, desenvolveu-se um estudo, no decorrer de 1996 e início de 1997, com vistas a identificar estas barreiras em uma amostra de 184 profissionais da área de educação. Neste estudo, utilizou-se uma técnica aberta idealizada pela autora, com base em um exercício proposto por Necka (1992) para identificar apenas barreiras internas à expressão da capacidade pessoal para criar. Esta consiste na seguinte sentença indutora, que deve ser completada de forma mais sincera e ampla possível: Eu seria mais criativo(a) se... Os sujeitos foram solicitados a completá-la durante seminários sobre criatividade em sala de aula, conduzidos pela autora em distintas cidades brasileiras. Esta técnica, por seu caráter aberto, permite obter informações sobre aqueles fatores que o sujeito considera como um freio à sua expressão criativa.

Realizou-se análise de conteúdo, elaborando-se categorias que permitiram abranger o conteúdo referente às barreiras à criatividade pessoal. É relevante destacar que o que os sujeitos referiam como barreiras à sua criatividade não representa necessariamente as barreiras reais, podendo existir uma apreciável distância entre o que o sujeito identifica conscientemente como um freio e o que realmente possa estar funcionando como tal.

Uma análise das respostas obtidas apontou cinco categorias principais de barreiras, a saber: (a) emocionais; (b) sócioculturais; (c) motivacionais/personalidade; (d) de disponibilidade de tempo; (e) intelectuais. Observou-se nesse estudo que as barreiras apresentadas por um maior número de sujeitos foram as de natureza emocional, bem como as de ordem sóciocultural, chamando a atenção tanto para fatores psicodinâmicos quanto sociodinâmicos, que dificultam ao indivíduo expressar e realizar o seu potencial criativo (Alencar, Oliveira, Ribeiro e Brandão 1996). Algumas das respostas apresentadas pelos sujeitos relativas às distintas dimensões identificadas são apresentadas a seguir:

Eu seria mais criativo se...

- Não fosse o medo que tenho das opiniões dos outros. O medo do ridículo ou de errar, me faz tremer e aí não consigo nem ter idéias.

- Tivesse tido mais oportunidades na minha infância.

- A sociedade e a escola na qual estudei não tivessem podado a minha criatividade.

- Cultivasse mais a calma, deixando de lado a insegurança e o medo de enfrentar o novo.

- Houvesse mais incentivo, motivação e liberdade.

- Fosse menos criticada ou não tivesse tanto medo de ser criticada.

- Meu português fosse melhor e não houvesse risco de cometer tantos erros.

- Não tivesse tanta preguiça de pensar e buscar idéias para colocá-las em prática.

- Conseguisse afastar o dragão do medo, da crítica destrutiva.

- Acreditasse na minha capacidade criativa.

- Dispusesse de mais conhecimentos.

- Tivesse mais tempo para elaborar minhas idéias. 
Um segundo estudo, utilizando a mesma técnica, foi realizado com uma amostra de 290 profissionais de educação de três países - Brasil, Cuba e Portugal (Alencar \& Mitjáns, 1998). Uma análise das respostas obtidas indicou diferenças entre os profissionais dos distintos países quanto às barreiras mais freqüentes. Constatou-se, por exemplo, que barreiras de ordem social foram mais apontadas pela amostra cubana, ao passo que entre os brasileiros e portugueses foram as barreiras de ordem pessoal as mais freqüentemente lembradas.

Com base nas respostas obtidas referentes às distintas modalidades de barreiras e na literatura da Psicologia da Criatividade sobre o tema construiu-se a primeira versão de uma escala para identificar as barreiras pessoais à expressão da criatividade. Foram seguidos os passos especificados abaixo:

1. Construção de 84 itens relativos às distintas categorias de barreiras à criatividade identificadas em pesquisas de nossa autoria citadas anteriormente, bem como na literatura sobre o tema.

2. Avaliação semântica dos itens construídos a fim de se garantir a sua compreensão, evitando ambigüidade e formulações pouco apropriadas. Para tal, 15 estudantes do segundo grau foram entrevistados individualmente por três bolsistas de Iniciação Científica. Durante a entrevista, procedia-se a uma leitura em voz alta de cada item do instrumento, devendo o sujeito repetir, com suas próprias palavras, o conteúdo referente ao mesmo. Ouviu-se ainda a opinião dos entrevistados a respeito do conteúdo dos itens e do instrumento como um todo.

3. Após esta etapa, procedeu-se à reformulação de alguns itens, nos quais foi detectada falta de clareza, eliminando-se ainda aqueles com conteúdos similares. Deste procedimento, resultou um inventário com 70 itens, a que denominamos Inventário para Identificação de Barreiras à Criatividade Pessoal.

4. Aplicação do instrumento construído em uma amostra de estudantes universitários com vistas a obter dados para a validação estatística do instrumento. A amostra utilizada para este fim incluiu 204 estudantes do sexo masculino e 185 do sexo feminino (dois sujeitos omitiram esta informação), tendo 83,7\% da amostra entre 17 e 23 anos. Os estudantes representavam distintos cursos, como Arquitetura, Biologia, Ciências Políticas, Educação Física, Engenharia, Estatística, Letras, Medicina, Pedagogia, Psicologia e Química e 35,3\% informaram que também trabalhavam.

5. Utilizou-se, para análise dos dados do estudo, o pacote estatístico SPSS (Statistical Package for the Social Sciences) for Windows, versão 5.01, tendo sido feita inicialmente uma análise exploratória dos dados, com vista a verificar a normalidade das distribuições e os pressupostos da análise fatorial.

As análises fatorial e de fidedignidade do instrumento levaram à eliminação de quatro itens, reduzindo o número de itens de 70 para 66. 


\section{Resultados das análises fatoriais e de fidedignidade}

Procedeu-se a análise fatorial pelo processo de extração Análise dos Eixos Principais (PAF), com rotação oblíqua com os quatro fatores derivados. Os critérios de retenção dos fatores foram: eigenvalue igualou maiores do que 2,0; cargas fatoriais dos itens iguais ou maiores do que 0,30 e fator semanticamente interpretável. Os quatro fatores apontados pela análise serão descritos a seguir:

\section{Fator 1. Inibição/timidez}

O fator 1, denominado Inibição/timidez,inclui 23 itens relativos a aspectos de ordem especialmente emocional que bloqueiam a expressão da criatividade pessoal. O valor eigenvalue deste fator foi de 15,71 , explicando $22,4 \%$ da variância total e $60,87 \%$ da variância comum. O índice de consistência interna (Alfa) foi de 0,91. Os itens componentes deste fator com as respectivas cargas fatoriais e comunalidades são apresentados na Tabela 1. 
Tabela 1. Cargas Fatoriais e Comunalidades (h) para o Fator 1 Inibição/timidez

\begin{tabular}{|c|c|c|c|}
\hline Item & Conteúdo & Carg & $\mathrm{h}$ \\
\hline 2 & Fosse menos tímido(a) para expor minhas idéias & 0.71 & 0.44 \\
\hline 21 & Não tivesse medo de expressar o que penso & 0,69 & 0,56 \\
\hline 3 & Fosse mais espontâneo(a) & 0,64 & 0,38 \\
\hline 8 & Fosse mais corajoso(a) & 0,61 & 0,46 \\
\hline 5 & Não fosse tão inseguro(a) & 0,61 & 0,43 \\
\hline 26 & Fosse mais extrovertido(a) & 0,60 & 0,32 \\
\hline 25 & Não tivesse medo de executar minhas idéias & 0,59 & 0,48 \\
\hline 9 & Tivesse mais iniciativa & 0,54 & 0,41 \\
\hline 20 & Não tivesse medo de enfrentar as críticas & 0,53 & 0,44 \\
\hline 1 & Acreditasse mais em mim & 0,51 & 0,32 \\
\hline 7 & Não tivesse tanto medo de errar & 0,49 & 0,36 \\
\hline 6 & Estivesse disposto(a) a correr mais riscos & 0,48 & 0,27 \\
\hline 36 & $\begin{array}{l}\text { Não tivesse medo do que os outros irão pensar de } \\
\text { mim }\end{array}$ & 0,47 & 0,49 \\
\hline 30 & Não tivesse medo de ser incompreendido(a) & 0,46 & 0,36 \\
\hline 10 & Não tivesse medo de contrariar as pessoas & 0,44 & 0,28 \\
\hline 29 & $\begin{array}{l}\text { Aproveitasse melhor as oportunidades que surgem de } \\
\text { exercitar a minha criatividade }\end{array}$ & 0,41 & 0,38 \\
\hline 24 & Expressasse melhor as minhas idéias & 0,40 & 0,33 \\
\hline 28 & Não me sentisse inferior aos outros & 0,39 & 0,36 \\
\hline 50 & Eu valorizasse mais as minhas idéias & 0,35 & 0,33 \\
\hline 16 & Não tivesse medo de enfrentar o desconhecido & 0,34 & 0,27 \\
\hline 4 & Não fosse tão crítico(a) comigo mesmo(a) & 0,34 & 0,18 \\
\hline 57 & Tivesse menos medo do ridículo & 0,35 & 0,49 \\
\hline \multirow[t]{5}{*}{23} & Desse mais asas a minha imaginação & 0,31 & 0,36 \\
\hline & Eigenvalue $=15.71$ & & \\
\hline & Porcentagem da variância total $=22.4$ & & \\
\hline & Porcentagem da variância comum $=60.87$ & & \\
\hline & Alfa $=0.91$ & & \\
\hline
\end{tabular}

\section{Fator 2. Falta de tempo/oportunidade}

Este fator inclui 14 itens relativos especialmente à pouca disponibilidade de tempo, oportunidades e recursos para expressar o potencial para criar. O valor eigenvalue deste fator foi de 4,42, o que explica 6,3\% da variância total e 17,12\% da variância comum. O índice de consistência interna (Alfa) obtido foi de 0,85 . Os itens componentes deste fator com as respectivas cargas fatoriais e comunalidades são apresentados na Tabela 2. 
Tabela 2. Cargas Fatoriais e Comunalidades (h) para o Fator 2 Falta de tempo/ oportunidade.

\begin{tabular}{|c|c|c|c|}
\hline Item & Conteúdo & Carg & $\mathrm{h}$ \\
\hline 34 & $\begin{array}{l}\text { Tivesse mais oportunidade de pôr em prática as } \\
\text { minhas idéias }\end{array}$ & 0,63 & 0,54 \\
\hline 31 & Tivesse mais tempo para elaborar minhas idéias & 0,56 & 0,32 \\
\hline 15 & Tivesse mais tempo & 0,55 & 0,28 \\
\hline 41 & $\begin{array}{l}\text { Tivesse mais recursos (equipamentos, livros, dinheiro } \\
\text { etc) para colocar as minhas idéias em prática }\end{array}$ & 0,54 & 0,37 \\
\hline 37 & $\begin{array}{l}\text { Tivesse mais oportunidade para explorar o meu } \\
\text { potencial }\end{array}$ & 0,54 & 0,40 \\
\hline 49 & Houvesse mais cooperação entre as pessoas & 0,48 & 0,29 \\
\hline 54 & As pessoas valorizassem mais as idéias novas & 0,48 & 0,37 \\
\hline 35 & Fosse mais incentivado pelos colegas & 0,46 & 0,39 \\
\hline 18 & Houvesse maior reconhecimento do trabalho criativo & 0,45 & 0,24 \\
\hline 22 & $\begin{array}{l}\text { Tivesse sido mais estimulado(a) pelos meus } \\
\text { professores }\end{array}$ & 0,44 & 0,28 \\
\hline 40 & Tivesse tido mais liberdade para expor o que penso & 0,40 & 0,45 \\
\hline 47 & As minhas idéias fossem mais valorizadas & 0,39 & 0,46 \\
\hline 55 & Houvesse mais respeito às diferenças entre pessoas & 0,34 & 0,23 \\
\hline \multirow[t]{5}{*}{29} & $\begin{array}{l}\text { Aproveitasse melhor as oportunidades que surgem de } \\
\text { exercitar a minha criatividade }\end{array}$ & 0,31 & 0,38 \\
\hline & Eigenvalue $=4,42$ & & \\
\hline & Porcentagem da variância total $=6,30$ & & \\
\hline & Porcentagem da variância comum $=17,12$ & & \\
\hline & Alfa $=0,85$ & & \\
\hline
\end{tabular}

\section{Fator 3. Repressão social}

O fator 3, denominado Repressão social inclui 15 itens referentes a distintos aspectos de ordem social que bloqueiam a criatividade. O valor eigenvalue deste fator foi de 3,58, que explica 5,1\% da variância total e 13,9 da variância comum. Na Tabela 3, são apresentados os seus itens componentes com as respectivas cargas fatoriais e comunalidades. 
Tabela 3. Cargas Fatoriais e Comunalidades (h) para o Fator 3 Repressão social

\begin{tabular}{|c|c|c|c|}
\hline Item & Conteúdo & Carg & $\mathrm{h}$ \\
\hline 38 & Não tivesse recebido uma educação rígida & 0,58 & 0,37 \\
\hline 43 & $\begin{array}{l}\text { Tivesse tido mais oportunidade para errar sem ser } \\
\text { taxado(a) de burro(a) ou idiota }\end{array}$ & 0,57 & 0,52 \\
\hline 32 & Não tivesse sido podado(a) pela família & 0,53 & 0,39 \\
\hline 42 & Não tivesse sido podado(a) pelos meus professores & 0,50 & 0,44 \\
\hline 44 & Fosse menos criticado(a) & 0,49 & 0,37 \\
\hline 57 & Tivesse menos medo do ridículo & 0,48 & 0,49 \\
\hline 56 & Eu fosse menos autoritário(a) & 0,43 & 0,20 \\
\hline 53 & $\begin{array}{l}\text { Houvesse maior aceitação da fantasia no meio em } \\
\text { que vivo }\end{array}$ & 0,39 & 0,27 \\
\hline 36 & Não tivesse medo do que os outros irão pensar de mim & 0,39 & 0,49 \\
\hline 58 & Não fosse tão crítico(a) em relação às idéias dos outros & 0,37 & 0,15 \\
\hline 27 & Fosse menos perfeccionista & 0,34 & 0,14 \\
\hline 48 & Deixasse de dar ouvidos às críticas sobre as minhas idéias & 0,33 & 0,19 \\
\hline 51 & Houvesse menos competição entre as pessoas & 0,33 & 0,17 \\
\hline \multirow[t]{5}{*}{52} & Fosse mais encorajado(a) a expor o que penso & 0,30 & 0,44 \\
\hline & Eigenvalue $=3,58$ & & \\
\hline & Porcentagem da variância total $=5,10$ & & \\
\hline & Porcentagem da variância comum $=13,86$ & & \\
\hline & Alfa $=0,85$ & & \\
\hline
\end{tabular}

\section{Fator 4. Falta de motivação}

O fator 4, denominado Falta de motivação, inclui 20 itens relativos sobretudo à ausência de elementos motivacionais de ordem pessoal que facilitam a expressão da criatividade. Este fator apresentou valor eigenvalue de 2,13, que explica 3,0\% da variância total e 8,15\% da variância comum. Neste fator, de forma similar aos anteriores, o índice de consistência interna foi elevado (Alfa $=0,88)$. Na Tabela 4, encontram-se os itens componentes deste fator com as respectivas cargas fatoriais e comunalidades. 
Tabela 4. Cargas Fatoriais e Comunalidades (h) para o Fator 4 Falta de motivação

\begin{tabular}{clcc}
\hline Item & \multicolumn{1}{c}{ Conteúdo } & Carg & $\mathrm{h}$ \\
\hline 69 & Tivesse mais entusiasmo & $-0,68$ & 0,51 \\
67 & Concentrasse mais no que faço & $-0,60$ & 0,36 \\
68 & Fosse mais curioso(a) & $-0,57$ & 0,42 \\
12 & Fosse menos preguiçoso (a) & $-0,54$ & 0,27 \\
61 & Fosse mais dedicado(a) ao que faço & $-0,53$ & 0,32 \\
62 & Tivesse mais energia & $-0,53$ & 0,33 \\
46 & Fosse mais persistente & $-0,53$ & 0,33 \\
11 & Não fosse tão acomodado(a) & $-0,48$ & 0,28 \\
70 & Tivesse mais conhecimentos & $-0,46$ & 0,31 \\
65 & Fosse mais rico(a) em idéias & $-0,44$ & 0,37 \\
17 & Fosse mais observador(a) & $-0,44$ & 0,31 \\
64 & Fosse menos dependente das outras pessoas & $-0,42$ & 0,33 \\
14 & Fosse mais organizado(a) & $-0,39$ & 0,21 \\
13 & Tivesse mais motivação para criar & $-0,37$ & 0,27 \\
19 & Exercitasse mais o hábito de buscar idéias novas & $-0,37$ & 0,31 \\
63 & Tivesse mais senso de humor & $-0,36$ & 0,30 \\
23 & Desse mais asas a minha imaginação & $-0,34$ & 0,36 \\
39 & Tivesse mais oportunidade de acesso a informações & $-0,33$ & 0,31 \\
33 & Fosse mais inteligente & $-0,31$ & 0,16 \\
9 & Tivesse mais iniciativa & $-0,31$ & 0,44 \\
\hline & Eigenvalue = 2,13 & & \\
& Porcentagem da variância total = 3,0 & & \\
& Porcentagem da variância comum = 8,15 & & \\
& Alfa = 0,88 & & \\
\hline & & & \\
\hline
\end{tabular}

\section{Resultados das análises descritivas}

A média (em uma escala de 5 pontos) e o desvio-padrão apresentados pelos sujeitos nos quatro fatores encontram-se na Tabela 5, juntamente com os resultados do teste "t" de Student. Como pode ser observado nesta Tabela, foi no Fator 2, referente à falta de tempo e oportunidade, que se alcançou a média com valor mais elevado $(3,62)$, seguida pelo Fator I (Inibição/Timidez). A média com menor valor foi observada no Fator 3 (Repressão Social). Na amostra estudada, portanto, a falta de oportunidade e limitação de tempo são aspectos percebidos como principal barreira à expressão da criatividade pessoal, seguido por inibição e timidez. Pelo teste "t" observouse que a diferença entre a média apresentada pelos sujeitos e o ponto neutro da escala, isto é, 3, nos fatores 1 (Inibição/Timidez), 2 (Falta de Tempo/Oportunidade) e 4 (Falta de Motivação) foi significativamente superior ao ponto neutro, o que indica a presença destas barreiras entre os sujeitos que responderam ao instrumento. 
Tabela 5. Média, Desvio-Padrão e Valor "t" nos Quatro Fatores

\begin{tabular}{ccccc}
\hline Fatores & Média & Desvio-padrão & $t^{*}$ & $\mathrm{p}$ \\
\hline 1 & 3,58 & 0,81 & 14,11 & $<0,0001$ \\
2 & 3,62 & 0,11 & 15,86 & $<0,0001$ \\
3 & 3,05 & 0,81 & 1,22 & n.s. \\
4 & 3,45 & 0,80 & 11,08 & $<0,0001$ \\
\hline
\end{tabular}

${ }^{*}$ t entre a média e o ponto neutro da escala, isto é, 3 .

A fim de selecionar as variáveis que fariam parte da análise de regressão, foram computadas correlações de Pearson entre as variáveis independentes idade, semestre, sexo e trabalho e os distintos fatores de primeira ordem, observando-se correlações significativas entre sexo e fator 2 (Falta de Tempo/ Oportunidade) $\mathrm{r}=0,19 ; p<0,0001$ e sexo e Fator 4 (Falta de Motivação) $\mathrm{r}=$ 0,19; $p<0,0001$, indicando que os sujeitos do sexo feminino consideram-se como tendo menos disponibilidade de tempo/oportunidade (Fator 2) e menos motivação (Fator 4) para expressar a sua criatividade.

Observou-se ainda uma correlação significativa entre a variável Trabalho e Fator 2 (Falta de Tempo/Oportunidade) $r=-0,14 ; p<0,005$, indicando que as pessoas que não trabalham consideram-se como dispondo de menos oportunidade/tempo para expressar o seu potencial criador.

\section{Análises de regressão múltipla}

Foram computadas análises de regressão múltipla para o Fator 2 e as variáveis sexo e trabalho, cujas correlações se mostraram significativas. Na Tabela 6 encontra-se a regressão múltipla para a variável dependente Fator 2 - Falta de Tempo/Oportunidade. Como pode ser observado nesta Tabela, 4,9\% dos valores apresentados nas respostas ao Fator 2 (Falta de Tempo/Oportunidade) são preditos pelas variáveis independentes sexo e trabalho. Pelo coeficiente (3, pode-se perceber que os sujeitos do sexo feminino e os que não trabalham tendem a se perceber como tendo menos disponibilidade de tempo/oportunidade do que os sujeitos do sexo masculino e os que trabalham.

Tabela 6. Regressão Múltipla para a Variável Dependente Fator 2 Falta de tempo/oportunidade

\begin{tabular}{lccccc}
\hline Variável & $\mathrm{B}$ & $\mathrm{SE} \mathrm{B}$ & $\beta$ & $\mathrm{t}$ & $\mathrm{P}$ \\
\hline Sexo & $-0,26$ & 0,08 & $-0,17$ & $-3,39$ & 0,008 \\
Trabalho & $-0,19$ & 0,08 & $-0,12$ & $-2,32$ & 0,0207 \\
$\mathrm{R}=0,221$ & & & & & \\
$\mathrm{R}=0,04 \mathrm{~g}$ & & & & & \\
\hline
\end{tabular}

\section{Discussão}

Os dados obtidos, através das análises realizadas, sugerem que os distintos fatores identificados refletem diversas categorias de barreiras à expressão da criatividade pessoal. Todos os fatores apresentaram índices elevados de consistência interna e discriminam várias modalidades de barreiras apontadas na literatura de Psicologia da Criatividade. O primeiro e o quarto fatores estão mais diretamente ligados a barreiras emocionais, motivacionais e de personalidade extensivamente 
discutidas por estudiosos diversos, como Adams (1986), Alamshah (1972) e Alencar (1995, 1996). Numerosos estudos (sumarizados, por exemplo, por Alencar, 1995; Hayes, 1989; e Sternberg \& Lubart, 1995) têm chamado a atenção para a importância de vários traços de personalidade no funcionamento criativo. De forma similar, o papel fundamental de variáveis motivacionais na produção criativa foi especialmente salientado por Amabile (1983). Esta autora considera a motivação como um dos fatores essenciais para a produção criativa. Por outro lado, a interferência de barreiras emocionais no funcionamento criativo foi amplamente discutido por Adams.

Os Fatores 2 (Disponibilidade de Tempo/ Oportunidade) e 3 (Repressão Social) dizem respeito sobretudo a variáveis de ordem social que afetam a criatividade. Dentre os diversos estudiosos da criatividade que chamam a atenção para estes fatores, salientam-se Arieti (1974), Amabile (1983, 1991) e Montuori e Purser (1995). Notadamente, Amabile, em sua teoria da criatividade, destaca a influência das condições sociais na criatividade, apontando os diversos fatores que facilitam ou inibem a expressão e desenvolvimento do potencial para criar. Esta autora examinou comportamentos parentais que têm influência no desenvolvimento da criatividade, bem como características e comportamentos de professores e colegas que têm impacto na expressão do potencial criador. A influência adversa do autoritarismo e de mn comportamento restritivo por parte dos pais, bem como do dogmatismo, rigidez, sarcasmo, excesso de crítica por parte dos professores é salientada por esta autora.

Observou-se que as médias relativas ao Fator 1 (Inibição e Timidez), Fator 2 (Falta de Tempo e Oportunidade) e 4 (Falta de Motivação) foram significativamente superiores ao ponto médio na amostra utilizada para fins de validação do instrumento. Apenas no Fator 3 (Repressão Social) a diferença encontrada não foi significativa. Observa-se que o conteúdo deste último fator diz respeito a aspectos da socialização e características do meio social que inibem a expressão da criatividade. O resultado aqui encontrado com relação a este aspecto talvez possa ser explicado pelo perfil da amostra que respondeu ao instrumento (estudantes do $3^{\circ}$ grau de uma universidade pública, em sua grande maioria de status sócio-econômico médio). Menos autoritarismo e menos rigidez das práticas parentais parecem caracterizar os familiares de classe média, o que se refletiu nas respostas apresentadas aos itens componentes deste fator (Repressão Social).

Por outro lado, Falta de Tempo/Oportunidade foi o aspecto mais apontado como barreira à expressão da criatividade pelos sujeitos que participaram do estudo, observando-se ainda que foram os estudantes do sexo feminino e os que não trabalhavam os que tendiam a se perceber como tendo menos disponibilidade de tempo/oportunidade. Tais resultados com relação à variável trabalho são difíceis de serem interpretados. Era nossa expectativa que o inverso fosse ocorrer, ou seja, aqueles estudantes que trabalhavam é que se considerariam como dispondo de menos tempo e oportunidade, o que não aconteceu.

Quanto aos resultados relativos à variável sexo, observou-se também que a amostra feminina considerou-se como tendo menos motivação para expressar a sua criatividade. Esta menor motivação poderia ajudar a explicar a percepção de menos disponibilidade de tempo e oportunidade por parte desta amostra. É relevante examinar esta variável em estudos futuros no sentido de verificar se os resultados aqui encontrados se mantêm, ampliando ainda a amostra para profissionais de áreas diversas, o que pretendemos investigar em estudo próximo.

Consideramos o estudo aqui apresentado como o primeiro de uma série de outros que deverão ser desenvolvidos com vistas a levantar dados relativos sobretudo à validade do instru- 
mento. Sugere-se, por exemplo, que dados obtidos através deste instrumento sejam comparados com outros levantados através de outras técnicas. Sugere-se também comparar grupos de profissionais mais e menos criativos nas diversas modalidades de barreiras, analisando-se possíveis diferenças nas barreiras identificadas pelo instrumento. Lembramos também que o instrumento pode ter utilidade para fins de diagnóstico ou ainda em programas de treinamento e desenvolvimento pessoal.

Como barreiras à expressão da criatividade é um tópico altamente negligenciado pelos pesquisadores da área da criatividade, esperamos, com este estudo, chamar a atenção para a sua importância, além de oferecer um instrumento com possibilidades várias de uso e aplicação.

\section{Referências}

Adams, J.L. (1986). Conceptual blockbusting (3 ${ }^{\mathrm{a}}$ ed.). New York: Addison-Wesley.

Alamshah, E. (1972). Blockages to creativity. Journal of Creative Behavior, 6, 105-113.

Alencar, E.M.L.S. (1995a). Como desenvolver o potencial criador (3ª ed.). Petrópolis: Vozes.

Alencar, E.M.L.S. (1995b). Criatividade (2a ed.). Brasília: Editora da Universidade de Brasília.

Alencar, E.M.L.S. (1996). A gerência da criatividade. São Paulo: Makron.

Alencar, E.M.L.S. e Mitjáns, A. (1998). Barreiras à expressão da criatividade entre profissionais brasileiros, cubanos e portugueses. Psicologia Escolar e Educacional, 2 (1), 23-32.

Alencar, E.M.L.S.; Oliveira, A.C.; Ribeiro, R. e Brandão, S.N. (1996). Barreiras à expressão da criatividade entre profissionais da área de educação (Resumo). Em Sociedade Brasileira de Psicologia (Org.), XXVI Reunião Anual de Psicologia (113). Ribeirão Preto: SBP.

Amabile, T.M. (1983). The social psychology of creativity. New York: Springer-Verlag.

Amabile, T.M. e Gryskiewics, N.D. (1989). The Creative Environment Scales: Work Environment Inventory. Creativity Research Journal, 2, 231-253.

Arieti, S. (1976). Creativity. The magic synthesis. New York: Basic Books.

Bruno-Faria, M.F. (1996). Estímulos e obstáculos à criatividade no ambiente de trabalho de uma instituição financeira. Dissertação de Mestrado. Universidade de Brasília, Brasília.

Bruno-Faria, M.F. e Alencar, E.M.L.S. (1996). Estímulos e barreiras à criatividade no ambiente de trabalho. Revista de Administração, 31 (2), 50-61.

Bruno-Faria, M.F. e Alencar, E.M.L.S. (1998). Indicadores de clima para a criatividade: um instrumento de medida da percepção de estímulos e barreiras à criatividade no ambiente de trabalho. Revista de Administração, 33 (4), 86-91.

Hayes, J.R. (1989). Cognitive processes in creativity. Em J.A. Glover; R.R. Ronning e C.R. Reynolds (Eds.), Handbook of Creativity. (pp. 135-145). New York: Plenum Press.

Isaksen, G. e Dorval, K.B. (1993). Toward an improved understanding of creativity within people: The levelstyle distinction. Em S.G. Isaksen; M.C. Murdock; R.L. Firestein e DJ. Treffinger (Eds.), Understanding and recognizing creativity. The emergence of a discipline. Norwood, N. J.: Ablex.

Montuori, A. e Purser, R.E. (1995). Deconstructing the lone genius myth: Toward a contextual view of creativity. Journal of Humanistic Psychology, 35 (3), 69-112.

Necka, E. (1992). Creativity training. Cracov, Polônia: Universitas.

Pames, SJ. (1967). Creative behavior guidebook. New York: Charles Scribner's.

Rickards, T. (1993). Creativity from a business school perspective: Past, present, and future. Em S.G. Isaksen; M.C. Murdock; R.L. Firestein e DJ. Treffinger (Eds.), Understanding and recognizing creativity. The emergence of a discipline. (pp. 155-176). Norwood, N. J. : Ablex.

Rickards, T. e Jones, LJ. (1991). Towards the identification of situationa1 barriers to creative behaviors: The development of a self-report inventory. Creativity Research Journal, 4, 303-315.

Schwartz, I. (1992). O momento criativo. Mito e alienação na ciência moderna. São Paulo: Best Seller.

Stemberg, R.J. e Lubart, T.I. (1995). Defying the crowd: Cultivating creativity in a culture of conformity. 
New York: Free Press.

VanDemark, N.L. (1991). Breaking the barriers in everyday creativity. Buffalo, New York: The Creative Education Foundation.

Recebido: 29/09/99

Aprovado: 21/11/99 